\title{
An Investigation of Consumer Decision-Making Styles of Young-Adults in Malaysia
}

\author{
Safiek Mokhlis \\ Faculty of Management and Economics, Universiti Malaysia Terengganu \\ 21030 Kuala Terengganu, Malaysia \\ Tel: 60-9-6683-164 E-mail: safiek@umt.edu.my
}

\begin{abstract}
The purpose of this exploratory study was to investigate the consumer decision-making styles of young-adults in Malaysia. Exploratory factor analysis was conducted to determine the dimensions considered by young-adults in their transactions in the market. Seven reliable factors and their corresponding decision-making styles were identified: Novelty, Brand Conscious Consumer; Perfectionistic, High-Quality Conscious Consumer; Confused by Overchoice; Recreational, Hedonistic Consumer; Impulsive, Careless Consumer; Variety-Seeking and Habitual, Brand-Loyal. Comparison was made with other studies to identify differences and similarities of consumer style factor structures across different countries.
\end{abstract}

Keywords: Consumer decision-making styles, Young-adults, Malaysia

\section{Introduction}

Young-adult consumers provide an interesting topic for the consumer research for at least four reasons (Grant and Waite, 2003). First, at the period of transition from adolescence to early adulthood, the young people seek to establish their own individual personas and form behaviour patterns, attitudes, and values, hence their own consumption patterns. They make purchases to define themselves and to create an identity of their own making (Holbrook and Schindler, 1989). Many of these patterns are carried well into individual's lifetimes (Moschis, 1987). Secondly, young people are able to influence the purchase and decision-making of others (Grant and Waite, 2003). Thirdly, they act as a change agent by influencing society and culture (Leslie et al. 2001). And finally, from a marketing perspective, young adults are recognised as a specialised market segment that forms a powerful consumer spending group in their own way (Moschis, 1987; Grant and Waite, 2003).

One specific group of young-adult population in Malaysia that represents the most lucrative market segment is college students. Despite the fact that the majority of college students are unemployed and their 'earning' comes mainly from educational loans and parental contributions, college students represent an extremely large and important market segment for many products and services. They are seen as a lucrative market since they have higher than average lifetime earnings and are just beginning a major transition period which is a key time to change previous behaviours (Warwick and Mansfield, 2000). Marketers are keen to target this group because they perceive them as potential loyal customers both currently and in the future (Feldman, 1999; Speer, 1998).

The rapid growth of college student population in Malaysia over the past two decades has been largely attributable to the government policy of expanding the tertiary education facilities through public as well as private institutions (Government of Malaysia, 2006). With the expansion of tertiary educational services, which resulted in the establishment of 20 public universities and many more private colleges, the number of students in further and higher education has been increasing steadily over the years. Recent statistics showed that the number of students entering local public universities for undergraduate studies rose dramatically from 29,962 in 2001 to 58,304 in 2006 - a 95 per cent increase within a five year period (Ministry of Higher Education, 2007). The government policy to have at least $35 \%$ of the labor force with tertiary education should see this growth continue in the future (Government of Malaysia, 2001).

While this segment is a potentially lucrative target for many marketers, it is also complex and must be examined carefully. One aspect of consumer behaviour of college students that deserve investigation is their decision-making styles. In this context, the Consumer Style Inventory (CSI) developed by Sproles and Kendall (1986) provides a potentially useful instrument to assist marketers in examining consumer decision-making styles. According to Sproles 
and Kendall (1986, p. 267), identification of decision-making styles among consumers "helps to profile an individual consumer style, educate consumers about their specific decision-making characteristics, and counsel families on financial management."

Since its introduction, the CSI has been tested using various nationalities - Americans (Sproles and Kendall, 1986; Lysonski et al. 1996), Koreans (Hafstrom et al. 1992), Chinese (Fan et al. 1997; Fan and Xiao, 1998; Hiu et al. 2001; Siu et al. 2001), New Zealanders (Durvasula et al. 1993; Lysonski et al. 1996), Greek (Lysonski et al. 1996), Indians (Lysonski et al. 1996; Canabal, 2001; Patel, 2008), Germans (Walsh et al. 2001; Walsh and Vincent, 2001), British (Mitchell and Bates, 1998), South African (Radder et al. 2006) and Turkish (Gonen and Ozmete, 2006; Kavas and Yesilada, 2007). Although these studies have shown that the CSI has a potential utility across international populations, there is not much known about the decision-making styles of young consumers in other Asian countries such as Malaysia. It is not clear yet if young Malaysian consumers follow the same behavioural patterns identified for other consumers in Asia and the United States or if they exhibit unique characteristics when confronting choices in the market. Therefore, this study takes a pioneering role in applying the scale to young-adult consumers in Malaysia.

This study has attempted to serve three purposes: (1) to examine the cross-cultural applicability of the CSI in Malaysia; (2) to identify the decision-making styles of the college students in Malaysia and (3) to compare the identified styles with the results of previous studies.

The remainder of this paper is divided into five sections. The next section provides an overview of Malaysia, the context of the study. This is followed by a brief review of past studies, research methodology, empirical results and concluding remarks.

\section{The Malaysian Context}

The landscape of the global economy has changed dramatically as Southeast Asia and other regions have taken an expanded role. Recent widespread economic in stability sparked by concerns about the purchasing power of Southeast Asian consumers illustrates the extent to which some of these once-small markets such as Malaysia have now become important players. Described as "Asia'a Tiger with a Vision" (Selvarajah, 1993), Malaysia is presently classified as an upper-middle income county and considered as one of the most developed of the developing countries.

Despite the challenging external environment, particularly during Asian financial crisis from 1997 to 1998, Malaysia generated an average Gross Domestic Product (GDP) growth of 6.2 per cent per annum from 1991 to 2005 . This growth more than doubled average household income from MYR1.169 per month in 1990 to MYR3,249 a month in 2004 (Government of Malaysia, 2006).

The retailing industry represents a significant part of the domestic economy. The rise of consumerism, increased urbanisation, higher disposable incomes, a rapidly rising population, a growth in consumption credit, a reduction in import duties and an influx of foreign investment and retailers have led to a dramatic expansion of the Malaysian retail industry. The sector recorded an average annual growth rate of 5.2 per cent in total sales from MYR159.6 billion in 2000 to MYR205.6 billion in 2005. By the end of 2005, the contribution of trade distributive sector to GDP increased from MYR26.8 billion in 2000 to MYR33.1 billion (Government of Malaysia, 2006). By this standard, the retail industry in Malaysia is expected to grow at an average rate of 6.8 annually and is anticipated to continue to be a prominent economic activity in the country.

In tune with the Government's aim to establish Malaysia as a prime regional shopping destination, many new shopping areas have been designated and many shopping campaigns and carnivals were launched to attract shoppers from local and abroad. The number of shopping complexes increased from 392 in 2000 to 550 in 2005. The number of shop units, being an integral feature of most housing developments as well as new and established townships, expanded at an average annual rate of 4.2 per cent (Government of Malaysia, 2006). Among the notable impacts of this development is that Malaysian consumers are increasingly exposed to and are selecting from a wider range of products, brands, quality and prices than ever before, thus increasing their confusion and need for consumer education. With the emergence of e-commerce, the complexity of decision making intensifies further. The business to consumer (B2C) e-commerce spending registered an increase from RM3.4 billion in 2000 to RM7.4 billion in 2005, as more companies and businesses offered their services direct to consumers through online transactions (Government of Malaysia, 2006).

Considering the scenario discussed above, consumer decision-making is of great interest for marketers and consumer educators interested in serving the consumer (Canabal, 2002). In order to develop the appropriate marketing strategies, the decision-making styles of consumers should be investigated thoroughly, keeping in mind the unique characteristics of the target consumers. The present study attempts to identify the decision making styles of young-adults in Malaysia, with an explicit focus on one homogeneous population - college students.

\section{Consumer decision-making styles}

A consumer decision-making style is defined as "a patterned, mental, cognitive orientation towards shopping and 
purchasing, which constantly dominates the consumer's choices. [... ] these traits are ever-present, predictable, central driving forces in decision-making. In essence we are speaking of a relatively enduring consumer personality, analogous to the more general concept of human personality in psychology" (Sproles, 1985, p. 79).

The examination on decision-making construct can be categorised into three major approaches: the psychographic/lifestyle approach (e.g., Wells, 1974), the consumer typology approach (e.g., Kenson, 1999; Ownbey and Horridge, 1997; Shim and Kotsiopulos, 1993) and the consumer characteristics approach (Sproles and Sproles, 1990; Walsh et al. 2001). Among these three approaches, the consumer characteristics approach has been widely acknowledged by consumer researchers as the most explanatory and powerful construct because it focuses on a cognitive and affective aspect of consumer behaviour. This approach deals with consumer's general predisposition toward the act of shopping and describing mental orientation of consumers in their decision-making process (Lysonski et al., 1996).

Based on examination of types of consumer decision-making styles in the previous literature, Sproles (1985) has identified 50 items related to consumers' cognitive and affective orientation towards shopping and buying. The author believes that measuring consumers' general orientations toward shopping and buying can identify their decision-making styles. The underlying assumption is that all consumers are thought to approach the market with certain fundamental decision-making orientations.

Sproles and Kendall (1986) have refined this inventory and accordingly developed a more parsimonious scale consisting of 40 items. The Consumer Style Inventory (CSI) that they have developed consists of eight mental characteristics of consumer decision-making styles namely: 1) perfectionistic and high-quality conscious; 2) brand conscious and price equals quality; 3 ) novelty and fashion-conscious; 4) recreational and hedonistic; 5) price conscious and value for money; 6) impulsive and careless; 7) confused by overchoice and 8) habitual and brand-loyal.

In an attempt to get a better understanding of consumer decision-making processes across different cultures, the CSI has been tested and validated in several countries. Hafstrom et al. (1992) examined the cross-cultural applicability of the CSI developed by Sproles and Kendall (1986) using a sample of Korean students. They found that five of the styles, Brand Consciousness, Quality Consciousness, Recreational Shopping Consciousness, Impulsiveness, and Confused-by-Overchoice, are common in both Korean and U.S. cultures. An additional factor of Time/Energy Conserving was suggested.

Durvasula et al. (1993) confirmed a high level of reliability and validity of the scale via the use of a sample of 210 undergraduate students in New Zealand. Lysonski et al. (1996) further investigated the cross-cultural applicability of the CSI using multi-country samples from India, Greece, U.S and New Zealand. While the CSI inventory received some support from these four different samples, the researchers noticed that the inventory appears to be more applicable to the economically developed countries (U.S. and New Zealand) than to the economically developing countries (India and Greece). More recently, some researchers attempted to adopt the CSI to profiles decision-making styles of consumers in China (Fan and Xio, 1998; Fan et al. 1997; Hiu et al. 2001; Siu et al. 2001), India (Canabal, 2002; Patel, 2008), United Kingdom (Mitchell and Bates, 1998), Germany (Walsh et al. 2001; Walsh and Vincent, 2001), South Africa (Radder et al. 2006) and Turkey (Gonen and Ozmete, 2006; Kavas and Yesilada, 2007).

There is a general consensus among researchers that decision-making styles can vary across cultures. Thus, CSI in its original form cannot be generalised to different countries without some modification. Rosenthal and Rosnow (quoted in Walsh et al. 2001) suggest that a study needs to be replicated at least fifteen times before results can be generalised, indicating that additional work on the CSI is necessary. Sproles and Kendall (1986) recommended using the inventory with different population groups to determine the generality of its applicability. The study reported in this article responds to these calls and extends the research stream into Malaysia. This study has attempted to serve three purposes: (1) to examine the cross-cultural applicability of the CSI in Malaysia; (2) to identify the decision-making styles of the college students in Malaysia and (3) to compare the identified styles with the results of previous studies.

\section{Methodology}

\subsection{The questionnaire}

A structured questionnaire was prepared for use in the survey based on literature review and objectives of the study. Consumer decision-making orientations were measured using the 40-items of Consumer Style Inventory (CSI), developed by Sproles and Kendall (1986). All scales were measured on a 5-point Likert-type scales ranging from strongly disagree to strongly agree. The reliabilities of the CSI Scale, according to Sproles and Kendall (1986), ranged from 0.48 to 0.76 . Scale items were translated into Malay language with minor changes in wording to clarify the meaning. Demographic items were related to (a) gender, (b) age, (c) residence and (d) state of origin.

To determine the potential effectiveness of the questionnaire, the researcher distributed the questionnaire to 20 undergraduate students. The test found no serious problems and minor amendments were made to the survey questions based on the verbal feedback received. The final result of the pilot test finally indicated that the questions had face validity. 


\subsection{Sampling and data collection}

The sample for the study comprised of traditional undergraduate students from one public university at the northeast of Malaysia, majoring in management and economics studies. Given the nature of the study, a non-probability (convenience) sampling was chosen. To provide an adequate level of confidence in this study, 450 respondents were selected for the survey.

The survey was taken in a controlled classroom environment; allowing for a stronger research design. Specifically, the researcher read a standard set of instructions to the class, informing them of the survey purpose and conditions and encouraged their participation in the study. Students were assured of the confidentiality of their responses and their names were not solicited. No inducements were offered to encourage the students to participate, although virtually all of the students who were asked did cooperate in the study. Students were given approximately 20 minutes to complete the questionnaire. Students were prevented from communicating with each other while the survey was in progress.

Of 442 returned questionnaires, a total of 419 responses deemed valid for data analysis, yielding a response rate of 94.8 percent. Such a response rate was considered sufficient for statistical reliability and generalisability (Tabachnick and Fidell, 2001) and most satisfactory especially when compared with previous research works on consumer decision making styles (e.g. Hafstrom et al. 1992; Durvasula et al. 1993; Lysonski et al. 1996; Canabal, 2001). This relatively high response rate was attributed to the self-administered approach undertaken in distributing the questionnaires.

The sample had a mean age of 21.9 years and consisted of 29.8 percent male and 70.2 percent female. The students were from different regions with diverse backgrounds ranging from urban to rural which also reflect their differences in socioeconomic status.

\subsection{Analysis}

The data were entered into the computer for statistical analysis with the application of the SPSS computer program. The first step in analyzing the data was to identify the salient items that explain the correlations among a set of variables. For this purpose, factor analysis with principal component method was conducted on decision-making style scale items. Factoring ceased when all eigenvalues of greater than one were obtained and when a set of factors explained a large percentage of the total variance was achieved. Bartlett test of sphericity was run to test the assumption that the variables are uncorrelated in the population. To test the appropriateness of factor analysis, Keiser-Meyer-Olkin (KMO) measure of sampling adequacy was assessed while the factor analysis was run. An accepted method of interpretation of factor loadings is to regard as significant any variable with a loading of 0.5 or greater as associated with the appropriate factor.

To assess the internal consistency of each factor group obtained, a reliability analysis was carried out. The assumption behind this approach is that the items of a measure work together as a set and should be capable of independently measuring the same construct. The items should be consistent in what they indicate about the concept being measured. The Cronbach alpha was used to measure internal reliability by unit weighting items with salient loadings in a factor where Cronbach's alpha coefficient at 0.4 or higher was considered acceptable (Sproles and Kendall, 1986).

\section{Results and interpretation}

The purpose of factor analyzing the 40-item inventory was to determine if the factors identified by previous researchers were common to the Malaysian sample. As a result of factor analysis, 28 items were retained in this study. Table 1 presents the results of an eight-factor solution for consumer decision-making style items. Factors are named in line with Sproles and Kendall (1986) when they reflect similar decision-making styles between U.S. and Malaysian consumers. Each factor consists of at least two items, indicating that the scales are multidimensional scales as opposed to unidimensional scale where all items would be loaded on just one factor.

The factor analysis shows that the items included in the questionnaire can be grouped in eight factors with eigenvalues ranging from 1.2 to 6.54 (see Table 1). Bartlett's test of sphericity is significant and the value of KMO statistic $(0.831)$ is also large $(\mathrm{p}<0.0001)$. Thus, factor analysis can be considered appropriate. However, the reliability analysis shows that factor 8 cannot be considered a reliable factor in the identification of decision-making styles of young Malaysian consumers (Alpha $<0.4$ ). The seven factor model explained $44.4 \%$ of the variance in the correlation matrix compared to $35 \%$ in Canabal (2002) and Fan and Xiao (1998), 47\% in Hafstrom et al. (1992), and 46\% in Sproles and Kendall (1986) for Indian, Chinese, Korean, and United States young consumers respectively.

\subsection{Interpretation of the factors}

Factor 1: With a combination of brand name, fashion and price as the important purchasing criteria, this factor can be conceptually named as Novelty, Brand Conscious consumer. Item loading on this factor indicates that consumers who score high on this factor are likely to buy best-selling and well-known brands that are the latest in style and expensive at nice department and specialty stores. They are also feels that highly advertised brands are very good choices. They believe that a product sold at a higher price means better quality. A Cronbach's alpha of 0.83 for this factor is considered as highly reliable. 
Factor 2: This factor depicts the characteristics of a consumer as Perfectionistic, High-Quality Conscious. Characteristics identified in this factor are a consumer who particularly concern in seeking high-quality products, to get the best value for money, tends to watch his/her spending and set a high standard of expectation for products. This factor is considered reliable with an alpha coefficient of 0.67 .

Factor 3: This factor implies a Confused by Overchoice consumer characteristic. High scorers on this characteristic perceive many brands and stores from which to choose from and the amount of information available to them about different products adds to confusion. As they experience information overload, they always get into trouble when making choices. This factor is considered reliable with an alpha of 0.59 .

Factor 4: This measure describes the consumer as Recreational, Hedonistic Conscious. Those scoring high on this dimension found shopping as an enjoyable and pleasant activity as they do not feel shopping wastes their time. In addition, they are gain excitement from shopping task by buying something new. This factor is accepted to be reliable with an alpha value of 0.65 .

Factor 5: This factor appears to measure a consumer style labeled as Impulsive, Careless Consumer. Consumers who score high on this factor tend to buy on the spur of the moment and later regret their impulsive behaviour. They are also unconcerned about getting best products by shopping quickly as they could. An alpha of 0.65 indicates that this factor is reliable.

Factor 6: This is a description of a consumer consciousness in seeking variation when making choice decision. Consumers with this characteristic tend to shop at different stores and change brands they buy regularly. This factor identifies a Variety-Seeking Consumer characteristic and is marginally reliable (0.42).

Factor 7: This factor measures Habitual, Brand-Loyal Consumer style. High scorers on this factor can be characterized as consumers who have favourite brands and stores and have formed habits by choosing them repetitively. Those scoring high identified themselves as consumers with strong feelings of loyalty by sticking to a favourite brand. This factor is considered reliable with an alpha of 0.52 .

\subsection{Comparison with other studies}

In this section, the results of this study are compared with the results of four selected previous studies: Sproles and Kendall (1986), Hafstrom et al. (1992), Canabal (2001) and Fan and Xio (1998). The "Brand Conscious" style is number one in the list of factors for the present study, the Korean, the Chinese and the Indian samples and second for the U.S. sample (see Table 2). The "Perfectionists" or "High-Quality Conscious" consumer is also identified among the top three factors for all four samples. However, a factor such as "Confused by Overchoice" is relatively more common among the Malaysian and Indian samples than it is for the Korean, the Chinese or the U.S. samples. It should be noted that for the Chinese sample (Fan and Xiao, 1998), the components of the "Confused by Overchoice" are similar to what the authors identified as "Information Utilization" style. Furthermore, it seems that the "Price-Value Conscious" style is more important for U.S. and Chinese samples than for Indians and Koreans as a factor. This factor however was not found in the present study.

The "Fashion Conscious" style, reported for U.S. consumers by Sproles and Kendall (1986) and not found by Hafstrom et al. (1992) for the Korean students and by Fan and Xio (1998) for the Chinese students, loaded some of the items in the "Novelty, Brand Conscious" style for the Malaysian sample. It could be interpreted that young Malaysian consumers who are fashion conscious derive pleasure from buying well-known brands that are the latest in style and expensive at nice department and specialty stores. Also identified for the Malaysian sample was a style labeled "Time-Energy Conserving" similar to the one found in Korean consumers but with different item loadings. However, as with the Korean sample, this factor was not considered a reliable scale. Clearly, additional research is needed on the interrelation of these styles.

\section{Concluding remarks}

This study investigates the applicability of the CSI to the Malaysian culture by examining its factor structure, validity and reliability. Seven reliable factors of consumer decision-making styles were identified in this study: Novelty, Brand Conscious Consumer; Perfectionistic, High-Quality Conscious Consumer; Confused by Overchoice; Recreational, Hedonistic Conscious Consumer; Impulsive, Careless Consumer; Variety-Seeking and Habitual, Brand-Loyal. Overall results of this study compare favourably to those of the Sproles and Kendall's (1986) original study and have provided a general support to the inventory. The most important finding is that there is an indication of the generality of several consumer decision-making styles of young U.S. and Malaysian consumers. Given this finding, there is reason for cautious optimism that the CSI has elements of construct validity and has potential use across international populations. The implication is that the inventory is a suitable device to be used in understanding the behaviour of young consumers in Malaysia.

Comparing decision-making styles of consumers from different countries contributes to the understanding of the effect 
of the market environment as well as cultural factors impacting on consumer decision-making styles (Fan and Xiao, 1997). This study has made the first attempt to apply the CSI to the college students in Malaysia. The cross-cultural examination reinforces the inventory as a universal theory in the area of decision-making style. Moreover, it provides information to marketers interested in the decision-making profile of young-adult consumers in Malaysia so that they may gear their efforts accordingly.

\section{References}

Canabal, M. E. (2001). Decision Making Styles of Young South Indian Consumers: An Exploratory Study. College Student Journal, 36 (1), 12-19.

Durvasula, S., Lysonski, S. \& Andrews, J. C. (1993). Cross-Cultural Generalizability of a Scale for Profiling Consumers' Decision-Making Styles. Journal of Consumer Affairs, 27 (1), 55-65.

Fan, J. X. \& Xio, J. J. (1998). Consumer Decision-Making Styles of Young-Adult Chinese, Journal of Consumer Affairs, 32 (2), 275-294.

Fan, J. X., Xio, J. J. \& Xu, Y. (1997). Decision-Making Styles of Young-Adult Chinese Consumers: An International Comparison. Consumer Interests Annual, 43, 76-82.

Feldman, J. (1999). Back-to-school buying guide. Money, 28 (9), 165-168.

Gonen, E. \& Osemete, E. (2006). Decision-Making Styles of Young Turkish Consumers, Journal of the Home Economics Institute of Australia, 13 (1), 26-33.

Government of Malaysia. (2001). The Third Outline Perspective Plan 2001-2010. Kuala Lumpur: Percetakan Nasional Malaysia.

Government of Malaysia. (2006). Ninth Malaysia Plan 2006-2010. Putrajaya: Percetakan Nasional Malaysia.

Grant, I. C. \& Waite, K. (2003). Following the Yellow Brick Road - Young Adults' Experiences of the Information Super-Highway. Qualitative Market Research: An International Journal, 6 (1), 48-57.

Hafstrom, J. L., Chae, L. S. \& Chung, Y. S. (1992). Consumer Decision-Making Styles: Comparison between United States and Korean Young Consumers. Journal of Consumer Affairs, 26 (1), 146-158.

Hiu, A. S. Y., Siu, N. Y. M., Wang, C. C. L. \& Chang, L. M. K. (2001). An Investigation of Decision-Making Styles of Consumers in China. Journal of Consumer Affairs, 35 (2), 326-345.

Holbrook, M. \& Schindler, R. M. (1989). Some Explanatory Findings on the Development of Musical Tastes. Journal of Consumer Research, 16 (1), 119-124.

Kavas, A. \& Yesilada, F. (2007). Decision Making Styles of Young Turkish Consumers. European Journal of Economics, Finance and Administrative Sciences, 9, 73-85.

Kenson, K. M. (1999). A Profile of Apparel Shopping Orientation Segments among Male Consumers. Unpublished MA thesis, California State University Long Beach.

Leslie, E., Sparling, P. B. \& Owen, N. (2001). University Campus Settings and the Promotion of Physical Activity in Young Adults: Lessons from Research in Australia and the USA. Health and Education, 101 (3), 116-125.

Lysonski, S., Durvasula, S. \& Zotos, Y. (1996). Consumer Decision-Making Styles: A Multi-Country Investigation. European Journal of Marketing, 30 (12), 10-21.

Ministry of Higher Education Malaysia (2007). http://www.mohe.gov.my/web_statistik

Mitchell, V. W. \& Bates, L. (1998). UK Consumer Decision-Making Styles. Journal of Marketing Management, 14, 199-225.

Moschis, G. P. (1987). Consumer Socialization: A Life Cycle Perspective, Lexington, MA: Lexington Books.

Ownbey, S. F. \& Horridge, P. E. (1997). Acculturation Levels and Shopping Orientations of Asian-American Consumers. Psychology \& Marketing, 14 (1), 1-18.

Patel, V. (2008). Consumer Decision Making Styles in Shopping Malls: An Empirical Study. In U. Dhar et al. (Eds.), New Age Marketing: An Emerging Realities (pp. 627-637). New Delhi: Excel Books.

Radder, L., Li, Y. \& Pietersen, J. J. (2006). Decision-Making Styles of Young Chinese, Motswana and Caucasian Consumers in South Africa: An Exploratory Study. Journal of Family Ecology and Consumer Science, 34, 20 -31.

Selvarajah, C. T. (1993). The opening strategic windows for Australia and New Zealand in the Asia-Pacific: focus on Malaysia: the tiger with a vision, in Chin Tiong Tan et al. (eds.), Emerging International Strategic Frontiers Proceedings of the American Marketing Association International Marketing Conference in Singapore, American Marketing Association, pp. 48-52. 
Shim, S. \& Kotsiopulos, A. (1993). A Typology of Apparel Shopping Orientation Segments among Female Consumers. Clothing and Textiles Research Journal, 12, 73-85.

Siu, N. Y. M., Wang, C. C. M., Chang, L. M. K. \& Hui, A. S. Y. (2001). Adapting Consumer Style Inventory to Chinese Consumers: A Confirmatory Factor Analysis Approach. Journal of International Consumer Marketing, 13 (2), $29-47$.

Speer, T. (1998). College Come-Ons. American Demographics, 20 (3), 41-45.

Sproles G. B. \& Kendall, E. L. (1986). A Methodology for Profiling Consumers' Decision-Making Styles. Journal of Consumer Affairs, 20 (2), 267-279.

Sproles, E. K. \& Sproles, G. B. (1990). Consumer Decision-Making Styles as a Function of Individual Learning Styles. Journal of Consumer Affairs, 24 (1), 134-147.

Sproles, G. B. (1985). From Perfectionism to Fadism: Measuring Consumers' Decision-Making Styles. Proceedings, American Council on Consumer Interests, 79-85.

Tabachnick, B. G. \& Fidell, L. S. (2001). Using Multivariate Statistics, 4th ed. HarperCollins, New York.

Walsh, G., \& Vincent, W. (2001). German Market Mavens’ Decision-Making Styles. Journal of Euro-Marketing, 10 (4), 83-108.

Walsh, G., Mitchell, V. W. \& Thurau, T. H. (2001). German Consumer Decision-Making Styles. Journal of Consumer Affairs, 35 (1), 73-95.

Warwick, J. \& Mansfield, P. (2000). Credit Card Consumers: College Students' Knowledge and Attitude. Journal of Consumer Marketing, 17 (7), 617-626.

Wells, W. D. (1974). Life Style and Psychographics, Chicago: American Marketing Association. 
Table 1. Factor analysis of consumer decision making styles

\begin{tabular}{|c|c|c|c|}
\hline Items & Loadings & Eigenvalue & Variance \\
\hline \multicolumn{4}{|l|}{ Factor 1: Novelty, Brand Conscious Consumer } \\
\hline The well-known national brands are best for me & 0.75 & 6.54 & $11.33 \%$ \\
\hline The more expensive brands are usually my choice & 0.74 & & \\
\hline I prefer buying the best-selling brands. & 0.73 & & \\
\hline The most advertised brands are usually good choices. & 0.65 & & \\
\hline The higher the price of a product, the better its quality & 0.65 & & \\
\hline I keep my wardrobe up-to-date with the changing fashion & 0.58 & & \\
\hline Fashionable, attractive styling is very important to me & 0.55 & & \\
\hline \multicolumn{4}{|l|}{ Factor 2: Perfectionistic, High-Quality Conscious } \\
\hline When it comes to purchase products, I try to get the best. & 0.67 & 3.45 & $8.08 \%$ \\
\hline I look carefully to find the best value for the money. & 0.65 & & \\
\hline In general, I usually try to buy the best overall quality. & 0.55 & & \\
\hline I carefully watch how much I spend. & 0.60 & & \\
\hline I should plan my shopping more carefully than I do. & 0.52 & & \\
\hline I take the time to shop carefully for the best buys. & 0.52 & & \\
\hline \multicolumn{4}{|l|}{ Factor 3: Confused by Overchoice Consumer } \\
\hline There are many brands to choose that often I feel confused. & 0.63 & 2.32 & $5.77 \%$ \\
\hline All the information I get on different products confuses me. & 0.52 & & \\
\hline The more I learn about products, the harder to choose the best. & 0.69 & & \\
\hline \multicolumn{4}{|l|}{ Factor 4: Recreational, Hedonistic Conscious } \\
\hline Shopping is not a pleasant activity to me. & 0.75 & 1.84 & $5.47 \%$ \\
\hline Shopping the stores wastes my time. & 0.68 & & \\
\hline Shopping is one of the enjoyable activities of my life. & 0.54 & & \\
\hline \multicolumn{4}{|l|}{ Factor 5: Impulsive, Careless Consumer } \\
\hline I am impulsive when purchasing. & 0.62 & 1.39 & $5.04 \%$ \\
\hline I shop quickly, buying the first product or brand. & 0.63 & & \\
\hline Often I make careless purchases I later wish I had not. & 0.53 & & \\
\hline \multicolumn{4}{|l|}{ Factor 6: Variety-Seeking Consumer } \\
\hline To get variety, I shop different stores and brands. & 0.62 & 1.35 & $4.43 \%$ \\
\hline Fashionable, attractive styling is important for me. & 0.52 & & \\
\hline \multicolumn{4}{|l|}{ Factor 7: Habitual, Brand-Loyal Consumer } \\
\hline I go to the same stores each time I shop. & 0.70 & 1.25 & $4.29 \%$ \\
\hline Once I find a product or brand I like, I stick with it. & 0.58 & & \\
\hline \multicolumn{4}{|l|}{ Factor 8: Financial, Time-Energy Conserving } \\
\hline I make my shopping trips fast. & 0.55 & 1.20 & $3.94 \%$ \\
\hline The lower price products are usually my choice. & 0.51 & & \\
\hline
\end{tabular}


Table 2. Comparison with other studies

\begin{tabular}{|c|c|c|c|c|}
\hline $\begin{array}{l}\text { Present study: } \\
\text { Malaysia }\end{array}$ & $\begin{array}{c}\text { Canabal (2002): } \\
\text { India }\end{array}$ & $\begin{array}{c}\text { Fan and Xio } \\
\text { (1998): } \\
\text { China }\end{array}$ & $\begin{array}{l}\text { Hafstrom et al. } \\
\qquad(1996): \\
\text { South Korea }\end{array}$ & $\begin{array}{l}\text { Sproles and Kendall } \\
\text { (1986): U.S. }\end{array}$ \\
\hline $\begin{array}{l}\text { Novelty, Brand } \\
\text { Conscious }\end{array}$ & Brand conscious & Brand Conscious & Perfectionistic & Perfectionistic \\
\hline $\begin{array}{l}\text { Perfectionist, } \\
\text { High-Quality } \\
\text { Conscious }\end{array}$ & $\begin{array}{c}\text { High-Quality } \\
\text { Conscious/Perfectionist }\end{array}$ & Time Conscious & $\begin{array}{c}\text { Recreational/ } \\
\text { Shopping Conscious }\end{array}$ & Brand Conscious \\
\hline $\begin{array}{l}\text { Confused by } \\
\text { Overchoice }\end{array}$ & Confused by Overchoice & Quality Conscious & $\begin{array}{l}\text { Confused by } \\
\text { Overchoice }\end{array}$ & $\begin{array}{l}\text { Novelty/Fashion } \\
\text { Conscious }\end{array}$ \\
\hline $\begin{array}{l}\text { Recreational, } \\
\text { Hedonistic } \\
\text { Conscious }\end{array}$ & $\begin{array}{l}\text { Impulsive/Brand } \\
\text { Indifferent }\end{array}$ & Price Conscious & $\begin{array}{l}\text { Time-Energy } \\
\text { Conserving* }\end{array}$ & $\begin{array}{c}\text { Recreational, } \\
\text { Shopping Conscious }\end{array}$ \\
\hline $\begin{array}{c}\text { Impulsive, Careless } \\
\text { Consumer }\end{array}$ & Time Conscious* & $\begin{array}{l}\text { Information } \\
\text { Utilization }\end{array}$ & Impulsive & $\begin{array}{l}\text { Price/Value } \\
\text { Conscious }\end{array}$ \\
\hline Variety-Seeking & Recreational Shopper & & $\begin{array}{c}\text { Habitual/ } \\
\text { Brand-Loyal* }\end{array}$ & Impulsive \\
\hline $\begin{array}{l}\text { Habitual, } \\
\text { Brand-Loyal }\end{array}$ & $\begin{array}{l}\text { Price/ } \\
\text { Value-Conscious* }\end{array}$ & & $\begin{array}{l}\text { Price/Value } \\
\text { Conscious* }\end{array}$ & $\begin{array}{l}\text { Confused by } \\
\text { Overchoice }\end{array}$ \\
\hline $\begin{array}{l}\text { Financial, } \\
\text { Time-Energy } \\
\text { Conserving* }\end{array}$ & Dissatisfied/Careless* & & & Habitual Brand-Loyal \\
\hline
\end{tabular}

*Factors with Cronbach alpha levels below 0.4

Factors appear in the order presented by the authors. 